Aletria, Belo Horizonte, v. 28, n. 4, p. 31-46, 2018

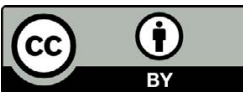

\title{
Espectros de Baldwin
}

\section{Baldwin's Specters}

\section{Jânderson Albino Coswosk}

Universidade do Estado do Rio de Janeiro (UERJ), Rio de Janeiro, Rio de Janeiro / Brasil jandersoncoswosk@gmail.com

\section{Maria Aparecida Andrade Salgueiro}

Universidade do Estado do Rio de Janeiro (UERJ), Rio de Janeiro, Rio de Janeiro / Brasil cidasal3@gmail.com

Resumo: O artigo explora a potência crítica e narrativa do documentário I Am Not Your Negro (2016), do diretor haitiano Raoul Peck (1953-), resultante de uma pesquisa intensa do diretor nos arquivos pessoais do escritor e ensaísta afro-americano James Baldwin (1924-1987). Apontaremos de que modo Baldwin, através da manipulação imagética e textual proposta por Peck, ressuscita questões graves da história das tensões raciais nos Estados Unidos, que dividiram o país antes e após o início dos anos 1970, ou ainda, após a luta pelos direitos civis e a morte de seus três grandes amigos: Martin Luther King Jr., Medgar Evers e Malcolm X. Evidenciaremos como o documentário expõe um pano de fundo do passado que se confunde com imagens, narrativas, corpos e nomes do presente, ao destacar a importância das reflexões de Baldwin para a luta contra o racismo e a violência ainda impostos à população negra estadunidense na contemporaneidade.

Palavras-chave: James Baldwin; Raoul Peck; racismo e violência; manipulação imagética e textual.

Abstract: We explore the critical and narrative perspectives of the documentary I am not your Negro (2016), structured after intense research over African-American writer James Baldwin's (1924-1987) personal archives. We attempt to show how Baldwin, through imagery and textual manipulation, resurrects important aspects of the racial issues history in the United States, which divided the country before and after the beginning of the 1970s, as well as after the Civil Rights Movement and the death of 
his three best friends: Martin Luther King Jr., Medgar Evers, and Malcolm X. We also call the reader's attention to the way the documentary exposes past and present images, narratives, bodies, and names, inside the same flow, highlighting the importance of Baldwin's reflections on the fight against racism and violence that still hang over the African-American population in contemporary times.

Keywords: James Baldwin; Raoul Peck; racism and violence; imagery and textual manipulation.

You gave me a language to dwell in, a gift so perfect it seems my own invention. ${ }^{1}$

Por que James Baldwin? Por que agora?

As perguntas que iniciam o presente artigo são sintomáticas e foram feitas por Stuart Hall, ${ }^{2}$ mas não direcionadas a Baldwin, e sim a Frantz Fanon, quando refletiu sobre a importância de se discutir a obra do psiquiatra martinicano naquele momento para se pensar o racismo e a psicopatologia do colonizado, bem como seus impactos nas lutas anticoloniais e contribuições para o campo dos Estudos Culturais, Póscoloniais, das Artes Visuais e da Literatura Comparada.

A apropriação da pergunta com o uso do nome do escritor, ensaísta e ativista dos direitos civis James Baldwin evoca o mesmo tom e a mesma urgência com a qual Hall gritou o nome de Fanon para trazê-lo de volta.

Sim, trazê-lo "de volta à vida", como um choque eletromagnético teórico-crítico, mas em um sentido derridiano de ser. Tal como Jacques Derrida evidenciou os rastros e heranças do marxismo nas sociedades contemporâneas em Espectros de Marx, ${ }^{3}$ presenciamos uma metodologia aproximada no documentário indicado ao Oscar I Am Not Your Negro (2016), do diretor haitiano Raoul Peck. A proposta cinematográfica de Peck põe em prática o exercício de trazer Baldwin à tona em seu caráter espectral, fantasmagórico, através de sua potência literária, ensaística e oratória. Nascido no Haiti, o aclamado diretor e presidente da escola francesa de cinema La Fémis vive, desde a infância, em um trânsito

\footnotetext{
${ }^{1}$ MORRISON. James Baldwin: His Voice Remembered; Life in His Language, p. 27.

${ }^{2}$ HALL. The Afterlife of Frantz Fanon: Why Fanon? Why Now? Why 'Black Skin, White Masks?', p. 6.

${ }^{3}$ DERRIDA. Espectros de Marx, p. 25.
} 
constante entre o Congo, a França, a Alemanha e os Estados Unidos. Além do documentário em evidência, também constam em seu currículo os filmes The Man by the Shore (1993), Lumumba (2000), Sometimes in April (2005) e The Young Karl Marx (2017).

A aproximação entre o diretor e o escritor deriva da própria vida nômade que o haitiano traça e das interseccionalidades culturais que atravessam sua(s) identidade(s). Da mesma maneira que Aimé Césaire, Jacques Stephen Alexis, Richard Wright, Gabriel García Marquez e Alejo Carpentier, James Baldwin tornou-se um de seus autores preferidos, pois escrevia sobre uma realidade com a qual Peck era familiarizado. Suas descrições a respeito da História e das relações humanas iam de encontro àqueles que viviam sob o fardo da era Jim Crow, da intitulada one-drop rule e da política segregacionista separate but equal. Mas também alcançavam outras geografias e realidades, tal qual a terra natal de Peck, o Haiti, primeiro país das Américas a se tornar livre da escravidão, em 1804. Peck argumenta que, assim como o legado africano nos Estados Unidos esteve fora das discussões históricas canônicas, a Revolução Haitiana foi ignorada pela história oficial, pois rema em sentido contrário à narrativa hegemônica - que congela e aprisiona a história haitiana nos porões da memória escravista e dos golpes militares. ${ }^{4}$ Ele conta que cresceu sob o mito de que havia apenas uma América, com um roteiro, cenário, atores, atrizes e hierarquia muito convincentes. ${ }^{5}$

Apesar de ter pouquíssimas obras traduzidas no Brasil e não mais reeditadas desde os anos 1960, do pouco impacto do lançamento do documentário no território brasileiro e de sua ausência em nossas universidades como referência de teses e dissertações, "[Baldwin] tem muito a dizer ao Brasil contemporâneo que começa a discutir a questão racial". ${ }^{6}$ Neto de um escravizado e nascido no Harlem em 1924, o escritor receberia mais tarde, além do sobrenome de seu padrasto, um pastor evangélico, a influência de uma retórica religiosa marcante que se mostraria presente em seus romances, ensaios e discursos. Diferente da religiosidade, sua produção escrita centrava-se em retratar não somente os reflexos das tensões raciais na vida da população negra, mas também a invisibilidade da cena gay afro-americana dentro e fora da comunidade negra estadunidense. Mesmo tendo sido um dos principais expoentes do

\footnotetext{
${ }^{4}$ PECK. Introduction on a Personal Note, p. ix.

${ }^{5}$ PECK. Introduction on a Personal Note, $\mathrm{p} . \mathrm{x}$.

${ }^{6}$ SALGUEIRO. A omissão como presença, p. 53.
} 
Movimento dos Direitos Civis, principalmente após a publicação de sua incisiva coletânea de ensaios The Fire Next Time (1963), Baldwin foi inúmeras vezes criticado por sua homossexualidade e negado por alguns de seus pares, quando decidiu se exilar em Paris e Istambul. Fica bem claro que o escritor se mostraria como uma das únicas figuras a tratar da invisibilidade do gay negro diante do discurso nacional e de sua própria comunidade, desde o lançamento de seus romances Go Tell It on The Mountain (1953) e Giovanni's Room (1956) e de seus ensaios em Nobody Knows My Name (1961).

Talvez tenha sido na tentativa de fazer "um filme impossível" que Raoul Peck conseguiu aproximar o mundo contemporâneo ao de Baldwin na sua mais pura espectralidade. Resultante de uma compilação de imagens fotográficas e televisivas do escritor, de seus textos literários e ensaísticos, I Am Not Your Negro é fruto de um desejo do diretor de explorar a obra do escritor afro-americano de maneira mais intimista. Um ano mais tarde, o diretor organizou pela Vintage Books todo o material do documentário em um livro, de mesmo título da obra cinematográfica. O haitiano perseguiu seu trabalho sem deixar-se apropriar da obra e discursos do escritor ou "traduzi-la", como ele mesmo diz:

Quero fazer um filme impossível. Impossível por muitas razões; impossível porque entrarei na mente de um autor, usando apenas suas palavras. Você o verá na tela, ouvirá sua voz e se convencerá de que ele está falando contigo, embora esteja morto. Quis habitar a mente de Baldwin sem traduzi-lo, sem me prostrar diante dele. Fiz algo novo na minha carreira cinematográfica, tornei-me modesto. Quis deixá-lo falar e não [...] finalizar o livro que ele estava tentando escrever. ${ }^{7}$

Na verdade, o documentário nasceu depois de anos a fio de intensa pesquisa nos arquivos pessoais do escritor, gentilmente cedidos por

\footnotetext{
7 "I want to make an impossible film. Impossible for many reasons; impossible because I am going to be inside the head of an author, using only his words, making you see him on screen, make you hear his voice and convince you he's talking to you, even though he is dead. I wanted to completely inhabit Baldwin without translating him, without standing in front of him. I did something new in my film career, I became modest. I wanted to let him speak, and not [...] finish the book he was trying to write". (PECK. I Am Not Your Negro: Director Raoul Peck talks Race, America and Film, p. 2, tradução nossa).
} 
sua irmã Gloria Karefa-Smart. Peck não fazia ideia por onde começar, pois recolheu um vasto aparato de fotografias, ensaios, cartas, notas e entrevistas daquele arquivo. Após quatro anos de tentativa de elaborar um roteiro original e "impossível" para o filme, o diretor recebe de Gloria um pacote com trinta páginas escritas, denominadas Notes Toward Remember This House, um projeto de um livro que Baldwin jamais terminaria de escrever. O principal ingrediente do filme, um livro inacabado, é um ensaio memorialístico iniciado em junho de 1979, no qual o escritor desejava expor a história das lutas pela igualdade social entre brancos e negros nos Estados Unidos, além da fabricação e manutenção do racismo naquele espaço, através da vida e morte de seus três grandes amigos: Martin Luther King Jr. (1929-1968), Medgar Evers (1925-1963) e Malcolm X (1925-1965).

Com a descoberta do texto inacabado, Peck sabia que seu desafio não era finalizar o texto que tinha em mãos, mas reunir as diversas vozes - os diversos espectros, a pluralidade, a potência de uma escrita aparentemente morta, estagnada pela impossibilidade de se ater à mão física do escritor, mas que ressurge com força ainda mais aguda e exibe sobrevida em seus traços à medida que é exposta lado a lado com a nostalgia segregacionista e as novas formas de violência contra a população negra que emergem na Afro-América contemporânea.

Em cinco anos, Martin, Medgar e Malcolm tiveram suas vidas ceifadas e impressas naquelas poucas e pesadas letras de Baldwin. $\mathrm{O}$ escritor não se ateve à cor de pele de seus amigos para buscar uma tangente entre suas vidas e a história do racismo nos Estados Unidos: eram suas lutas, suas causas, enfrentadas de modos muito diferentes, mas que no fim desmascaravam as armadilhas do racismo. É exatamente essa a evidência de que ambos - o escritor e o diretor - precisavam. ${ }^{8}$ Através dessas mortes e de suas reverberações, Baldwin desconstrói narrativas e auxilia Peck a conectar a história do Haiti à dos Estados Unidos, dentro de seus diferentes esquemas oriundos do doloroso e sangrento sistema escravista. Quando seguimos essa mesma trilha, Baldwin nos ajuda também a conectar as nossas histórias daqui - o nosso passado também doloroso e sangrento, o nosso racismo de cada dia, os nossos afetos.

I Am Not Your Negro, ao mesmo tempo em que parece um diário, nos sugere uma aproximação com a carta de Baldwin para seu sobrinho,

${ }^{8}$ PECK. Introduction on a Personal Note, p. xi. 
"My Dungeon Shook - Letter to My Nephew on the One Hundredth Anniversary of Emancipation", publicada em The Fire Next Time (1963), além de andar de mãos dadas com seus ensaios presentes em Notes of a Native Son (1955). As narrativas dos textos e imagens do documentário extrapolam a obra de Baldwin, estabelecendo conexões contemporâneas muito intensas com as cartas "The Pain Felt by Every Afro-Descendant", "A Letter to My Son", "A Message to My Daughter", entre tantas outras que compõem o livro The Travon Martin in US: An American Tragedy (2015), uma coletânea de cartas escritas por familiares que perderam parentes e amigos próximos por conta da violência policial. Em termos não só de temática, mas também de eloquência e sintaxe, presenciamos, ainda, a publicação de Between the World and Me (2015), do jornalista afro-americano Ta-Nahisi Coates (1975-), que toma emprestado o estilo de Baldwin para direcionar cartas ao filho de 14 anos, em desabafos profundos sobre o que significa (re)conhecer a presença afro-americana em espaços que, muitas vezes, lhe foram negados, e o que significa ser afro-americano na contemporaneidade, considerando a morte de Eric Garner e Travon Martin e de tantos outros nomes contemporâneos apontados em suas cartas. Parece sintomático esse tipo de escrita e de fala em primeira pessoa, sempre direcionada a alguém com quem se compartilha vida e sofrimentos comuns. A escrita em formato de cartas, de diários, herdeiros, de certa forma, de Baldwin, tem retornado com grande impulso na Afro-América contemporânea.

Todavia, Raoul Peck ultrapassa essa perspectiva: ao mesmo tempo em que se assemelha a um diário, o documentário toma a forma de uma montagem não linear, um mosaico. É feita uma colagem de entrevistas dos jornais, palestras e fotografias, alinhados ao texto de Baldwin. "Como encontrar as imagens apropriadas que ressonariam com as palavras escritas?"’ São as próprias palavras, eloquência e lucidez do escritor, na voz de Samuel L. Jackson, que nos guiam nessa dupla empreitada - a do escritor e a do diretor. Peck permitiu-se muito mais do que utilizar o texto inacabado de Baldwin: reestruturou parágrafos, períodos e às vezes alterou palavras, já que descobriu, ao longo da pesquisa e da compilação de textos e imagens, que Baldwin reescreveu as mesmas ideias e narrativas várias vezes e as corrigiu outras tantas vezes, até encontrar um destino para elas. Isso o permitiu utilizar a versão textual que melhor cabia para a

\footnotetext{
${ }^{9}$ STRAUSS. Editing I Am Not Your Negro, p. xxii.
} 
execução do filme, ou até mesmo misturar fragmentos de textos diferentes do escritor, mas sem ignorar seu processo criativo e estilo. ${ }^{10}$ Assim como com Toni Morrison (1987), Baldwin o havia presenteado com seus textos, personagens, estilo, sua própria "linguagem", mas que, ao presenteá-los, eram tomados pelo diretor como suas próprias invenções. ${ }^{11}$

O estabelecimento de um nexo possível entre o caráter fantasmático da linguagem de Baldwin e o traço de sobrevida conferido a sua escrita, aliado às imagens que ela produz, sugere um procedimento que revisita o gesto empregado pelo historiador da arte Aby Warburg, em seu Atlas Mnemosyne, de 1937. Ao montar 79 pranchas distintas com recortes de jornais, selos, moedas, obras de artes reproduzidas e fotografias, Warburg compõe inúmeras conexões aparentemente inconcebíveis entre artefatos de tempos históricos e espaços geográficos distintos, a fim de teorizar uma outra possibilidade de concepção e leitura do tempo histórico, ao contar, através da imagem, e não somente do texto, as formas sobreviventes da cultura.

A colagem e a montagem - métodos caros a Warburg e revisitados por Peck - tomaram enorme impulso com a reprodutibilidade técnica da imagem no século XIX e impactaram a maneira de se refletir sobre a historicidade da arte e o fazer artístico. O terreno vertiginoso preparado por Warburg em seu Atlas aponta para um abalo narrativo na história da arte através do uso da fotografia, quando articulado aos mais diversos gêneros artísticos e textuais. Esse abalo deixou diversas vias abertas no então modelo teleológico de pensar a historiografia da arte, ao também dar vasão, com o surgimento das práticas poéticas experimentais e visuais, à montagem enquanto método híbrido que articula o arquivo-documento com o plástico e o verbal, engendrando um protótipo de novas e múltiplas narrativas históricas em experimentação.

$\mathrm{Na}$ qualidade de um trabalho curatorial que "torna visíveis as sobrevivências, os anacronismos, os encontros de temporalidades contraditórias que afetam cada objeto, cada acontecimento, cada pessoa, cada gesto","12 a montagem-documentário de Raoul Peck elabora, tal como nos termos de André Malraux, ${ }^{13}$ um "museu imaginário" em torno da formação da sociedade estadunidense vinculada ao paradigma da

\footnotetext{
${ }^{10}$ PECK. Notes on the Writing Process, p. xvii-xix.

${ }^{11}$ PECK. Introduction on a Personal Note, p. xii.

${ }^{12}$ DIDI-HUBERMAN. Quando as imagens tocam o real, p. 212.

${ }^{13}$ MALRAUX. O museu imaginário.
} 
raça: a coleta de rastros, pistas em forma de imagens diversas, constrói um elo aparentemente não existente, a partir do qual o diretor, com sua perspicácia, seleciona, cola, monta e ordena essas imagens, sem uma hierarquização específica. As imagens em movimento exibem a complexidade do tempo à medida que passado e presente se fundem, permitindo que lacunas sejam preenchidas.

Através dessas lacunas, como que feridas abertas, Baldwin ressuscita questões graves da história das tensões raciais nos Estados Unidos, que dividiram o país antes e após o início dos anos 1970 ou, ainda, após a luta pelos direitos civis e a morte de seus companheiros de luta. Ao participar ativamente desse processo, e não simplesmente como compilador de dados, Peck descobriu como a percepção de Baldwin sobre a realidade estadunidense, nos anos 1960 e 1970, ainda exibia seus resíduos no contemporâneo.

O documentário se inicia com a seção Paying my Dues, com a exibição de falas de cidadãos brancos do Sul dos Estados Unidos, aliadas a imagens de jovens com cartazes anti-integração, com o destaque para a fotografia de Dorothy Counts, uma jovem negra de 15 anos que seguia seu caminho para uma escola predominantemente branca em Charlotte, na Carolina do Norte. Sentada em um banco, com o olhar de tristeza e revolta, suas costas exibiam risos, provocações, ódio e gritos de uma multidão que a vaiava, na tentativa de expulsá-la do colégio por conta da cor de sua pele. É este o starting point do filme, que exibe o retorno de Baldwin do exílio e sua perplexidade ao se deparar com a fotografia em Paris, e não estar em sua terra natal para defender a jovem garota:

Foi quando eu vi a fotografia. Diante de nós, em todos as bancas de jornais daquele amplo boulevard sombreado por árvores em Paris, havia fotografias de Dorothy Counts, uma menina negra de quinze anos [...]. Isso me deixou furioso, me encheu de ódio e pena. Deixou-me com vergonha. Alguém de nós tinha de estar lá com ela! Mas foi naquela tarde radiante que eu soube que deixaria a França. Eu simplesmente não podia mais ficar sentado em Paris, discutindo o problema argelino e o problema da Afro-América. Todo mundo estava fazendo sua parte, e era hora de eu ir para casa e fazer a minha. ${ }^{14}$

14 "That's when I saw the photograph. Facing us, on every newspaper kiosk on that wide, tree-shaded boulevard in Paris were photographs of fifteen-year-old Dorothy Counts 
Na seção Heroes, o filme explora a representação cultural do negro estadunidense no cinema no início do século XX, através da "metáfora do espelho" (mirror stage) ${ }_{1}^{15}$ quando recorre ao incontornável The Devil Finds Work (1976), obra na qual Baldwin faz questionamentos profundos do uso imagético do negro no cinema hollywoodiano. Para ele, Hollywood criou inúmeros estereótipos em torno dos negros estadunidenses, ao reforçar a superioridade dos personagens brancos sobre os negros nos filmes. ${ }^{16}$ Ao captar toda a capacidade crítica de cinematografia do escritor, Peck nos mostra que o afro-americano, enquanto criança, identifica-se com os heróis brancos da história oficial e da cinematografia hollywoodiana. Mais tarde, ele se enxerga no espelho e nota que não há semelhanças entre ambas as representações - a dos atores e de seu espectador negro. Com exibição de fragmentos de filmes de faroeste, Baldwin aponta a semelhança entre os indígenas e os negros - ambos sempre mortos nas películas e tidos como inimigos em potencial. Na esteira de The Devil Finds Work e com fragmentos dos filmes Dance, Fools, Dance (1931), Imitation of Life (1934) e Guess Who's Coming to Dinner (1967), Peck reimagina a história do cinema como um local de uma arqueologia racial, ao apontar como Hollywood se tornou um celeiro da perpetuação dos valores da supremacia branca.

$\mathrm{O}$ entrecruzamento de imagens da marcha de Selma e Ferguson, ao som de Damn Right I've Got the Blues (1991), de Buddy Guy (1936-); a aproximação de discursos de Malcolm X, Luther King, de fotos de Lorraine Hansberry (1930-1965) e excertos de sua peça A Raisin In The Sun (1959), pronunciados por Sidney Poitier, além das notas avulsas da escritora, exibidas por Baldwin, caminham rumo a um contrafluxo de páginas jornalísticas que apontam para o assassinato de Evers, notas do FBI Report, com descrições sobre Baldwin - único momento, aliás, em que aparece menção à homossexualidade do escritor. Esse seria o fim do

[...]. It made me furious, it filled me with both hatred and pity. It made me ashamed. Some one of us should be there with her! But it was on that bright afternoon that I knew I was leaving France. I could, simply, no longer sit around in Paris discussing the Algerian and the black American problem. Everybody else was paying their dues, and it was time I went home and paid mine" (BALDWIN apud PECK. I Am Not Your Negro: A Major Motion Picture Directed by Raoul Peck, from Texts by James Baldwin, p. 13, tradução nossa).

${ }^{15}$ BALDWIN. The Devil Finds Work, p. 25.

${ }^{16}$ BALDWIN. The Devil Finds Work, p. 34. 
ato Witness, apresentado por Bob Dylan em Only a Pawn in Their Game (1964), anúncio da morte de Evers.

Em Purity, terceiro ato do filme, as análises de Baldwin sobre a infantilização e hiperssexualização do negro no cinema se aprofundam com a figura de Sidney Poitier, algo que Stuart Hall discutiu de modo análogo em The Spectacle of the 'Other' ${ }^{17}$ A análise do ato confronta a perpetuação de um sonho americano associado a um cinema cuja base deveria reproduzir um estilo de vida à moda Gary Cooper e Doris Day, e de Ray Charles como metonímia da experiência subterrânea e negada da história afro-americana. ${ }^{18}$ Selling the Negro e I Am Not a Nigger, quarta e quinta etapas do documentário, anunciam a morte de seus dois outros amigos e, de certa forma, expõem um James Baldwin que se recusa a se colocar dentro de um discurso adepto ou ao ódio ou ao amor, embora as cenas televisivas e fotográficas, quando aproximadas de seus textos, fazem dos olhos do espectador reféns de tamanha violência cravada na história da inserção do corpo negro nos Estados Unidos. Inúmeras fotos da escravidão de africanos e afrodescendentes que se instaurou nas plantations do Norte e do Sul e sua justaposição com fotos de linchamentos, enforcamentos e paredões de revista policial em negros seminus instigam a ver que "a história do Negro nos Estados Unidos é a própria história desse país. E não é bonita."19

O documentário promove o contato entre o espectador e uma "rede semiótica do racismo" 20 na história pretérita e contemporânea dos Estados Unidos, que se alastra através da produção fílmica hollywoodiana, do poder que ela exerce sobre a hegemonia cultural em solo estadunidense e dos impactos da violência física e psíquica acometidos à população afroamericana através da ação policial, fincando suas raízes na instabilidade política gerada a partir da eleição de Donald Trump e nos embates raciais cada vez mais frequentes naquela nação.

A todo tempo, somos capturados por um framework do passado que se confunde com imagens, fatos, corpos, nomes do presente,

\footnotetext{
${ }^{17}$ HALL. The Spectacle of the 'Other', p. 77.

${ }^{18}$ BALDWIN apud PECK. I Am Not Your Negro: A Major Motion Picture Directed by Raoul Peck, from Texts by James Baldwin, p. 99.

19 "The history of the Negro in America is the history of America. And it is not a pretty story" (BALDWIN apud PECK. I Am Not Your Negro: A Major Motion Picture Directed by Raoul Peck, from Texts by James Baldwin, p. 95, tradução nossa).

${ }^{20}$ FERREIRA. Livro \#Paremdenosmatar evidencia genocídio da população negra, p. 2.
} 
reacendendo as lutas de outrora e ligando-as a situações contemporâneas vivenciadas pela população afro-americana. Retratos do passado se fundem aos do contemporâneo, formando um fluxo imagético único que leva o espectador a perceber que este é ainda um dilema que a AfroAmérica tem de enfrentar e que seu retrato está dentro de uma mesma moldura e mainstream.

Desse modo, o processo de montagem elaborado por Peck passa a ser, não somente a reunião de inúmeras vidas negras, vítimas da violência de cunho racial, mas também torna-se uma espécie de dissecagem, corte, de taxonomia de corpos ao longo do documentário. São recortes de corpos negros dilacerados, inferiorizados, expostos a um regime de visibilidade que denuncia essas mortes. Necroses, necrotérios, cadáveres e cemitérios ao ar livre. A superexposição espetacular desses corpos à morte com a ação policial, à desumanização, retira-lhes muito mais que a vida: afasta-os de sua dignidade. O controle sobre o direito à vida e morte, fomentado pelo Estado-nação, é designado por Achille Mbembe (2003) como "necropolítica": ${ }^{21}$ uma política que "decide" quem deve viver ou morrer, que encontra seus ecos no sistema carcerário estadunidense, nos censos educacionais no que concerne à população afro-americana, nessa violência nua e crua que atravessa inúmeros bairros e ruas das classes economicamente menos favorecidas. A voz de Baldwin denuncia a perda do controle sobre o corpo, sua representação dentro de um roteiro hollywoodiano branco e opressor, assim como de sua retaliação.

Mesmo que embebido, de certo modo, pelo espírito positivo dos direitos civis, Baldwin afirma que a população negra estadunidense está longe de viver em uma era "pós-racial", termo que ressurge das cinzas com a eleição de Barack Obama, em 2008. ${ }^{22}$ "Baldwin pode não ter sabido sobre Ferguson ou sobre o Black Lives Matter, sobre Obama e o ressurgimento de um nacionalismo branco, mas de certa forma ele explicou tudo isso antecipadamente". ${ }^{23}$ Ao insistir no quanto as artes negras ainda encenam os resíduos da escravidão e da segregação na Afro-

\footnotetext{
${ }^{21}$ MBEMBE. Necropolitics, p. 11.

${ }^{22}$ FRANCISCO. A utopia pós-racial nos Estados Unidos: reestruturação do racismo e a ascensão de Barack Obama na era do colorblindness, p. 3.

23 "Baldwin could not have known about Ferguson and Black Lives Matter, about the presidency of Barack Obama and the recrudescence of white nationalism in its wake, but in a sense he explained it all in advance" (SCOTT. Review: 'I am not your Negro' Will Make You Rethink Race, p. 2, tradução nossa).
} 
América, imersas na relação conflituosa entre as polaridades cromáticas "branco e preto", na tão visível violência e total negação a que o corpo negro é acometido, as falas de Baldwin sussurram os velhos fantasmas que atormentavam Fanon: o negro é refém de sua própria aparição, dada a visibilidade de seu tecido epitelial, que o antecede como um distintivo. ${ }^{24}$

Ao reduzir o corpo e o ser vivo a uma questão de aparência, de pele ou de cor, outorgando à pele ou à cor o estatuto de uma ficção de cariz biológico, os mundos euro-americanos em particular fizeram do negro e da raça duas versões de uma única e mesma figura, a da loucura codificada. Funcionando simultaneamente como categoria imaginária, material e fantasmagórica, a raça tem estado, no decorrer dos séculos precedentes, na origem de inúmeras catástrofes, e terá sido a causa de devastações físicas inauditas e de incalculáveis crimes e carnificinas. [...] Na sua dimensão fantasmagórica, é uma figura de nevrose fóbica, obsessiva e, porventura, histérica. ${ }^{25}$

Os Estados Unidos ainda vivem uma guerra interna que, embora preenchida de nuances raciais, é uma guerra pela posse do corpo e pelo desmantelamento dessas forças. Como desvincular a identidade da clausura do corpo e do confinamento representacional? Como desassociar o corpo negro daquilo que Cornel West nomeia de "combinação única do terrorismo estadunidense" 26 - corpos explorados pela escravidão e controlados pela segregação, e hoje confinados e assassinados em diferentes proporções?

É para além dessas imagens que Baldwin nos impulsiona a ver. É preciso pensar fora da ótica do chamado negro problem, ${ }^{27}$ o problema da "linha de cor" e da "dupla consciência" de que nos fala Du Bois, ${ }^{28}$ para se combater a latente e profunda desigualdade entre brancos e negros nos Estados Unidos.

\footnotetext{
${ }^{24}$ FANON. Pele negra, máscaras brancas, p. 152.

${ }^{25}$ MBEMBE. O devir-negro do mundo, p. 11.

26 "The unique combination of American terrorism" (WEST. Race Matters, p. XIII, tradução nossa).

${ }^{27}$ BALDWIN apud PECK, I am not your Negro: a major motion picture directed by Raoul Peck, from texts by James Baldwin, p. 35.

${ }^{28}$ DU BOIS. The Souls of Black Folk, p. 43.
} 
Baldwin, por meio de sua figura espectral captada pelo documentário, nos incita a ver outras imagens: ao invés de um corpo aprisionado numa zona de não ser profunda, como nos diria Fanon, ${ }^{29}$ na vitimização, na pena, no estereótipo, na condição de uma ameaça, ele aponta para imagens de protagonismo dos afrodescendentes na constituição da história de seu país. A integralização do passado e do presente, no documentário, o encontro interseccional entre corpos e histórias diversas exibem um novo corpo-nação, mais vivo e plural, fora das amarras raciais, da memória da escravidão e da segregação.

Enquanto montagem, ao fugir de um modelo teleológico de narrativa, I Am Not Your Negro promove a desierarquização dos corpos, de geografias e histórias. O trabalho de Peck, embasado na vida e obra de Baldwin, nos oferece muito mais do que uma via de mão dupla entre Literatura e Cinema, ou, nas palavras de Haroldo de Campos, é muito mais do que uma transposição tradutória de palavras escritas em imagens e sons. ${ }^{30}$ Nesse "contexto de mistura de gêneros", ${ }^{31}$ ele é capaz de nos alertar para a desconstrução de muros, barreiras linguísticas, raciais, de gênero, de classe e o quanto ainda é preciso ser feito para que esses embates sejam minimizados com uma revisão crítica de nossas histórias.

O documentário surge como luz no fim de um túnel onde James Baldwin ainda reluz como referência em nossas lutas, na tentativa de revisar as significações impostas ao nosso corpo, ao espaço em que vivemos, de derrubar monumentos e histórias de opressão. Apesar de sua ainda insipiente visibilidade no Brasil, assistir ao documentário pode nos instigar a pensar a nossa distância daquela "África" de Baldwin, mas também, de alguma forma, aproximá-la da nossa (o quanto essas "Áfricas" têm a nos dizer sobre esse movimento de ida e volta constante, de olhar o lá, a Afro-América, e olhar o cá, Afro-Brasil). É preciso revisar e instigar outros modos de usar aquelas reflexões feitas por Baldwin em espaços outros, que são nossos.

O trabalho de Peck se afasta da nostalgia ou da construção arqueológica de uma identidade, ${ }^{32}$ mas opta por "representar não a versão oficial das negociações, mas as acomodações, os compromissos,

\footnotetext{
${ }^{29}$ FANON. Pele negra, máscaras brancas, p. 102.

${ }^{30}$ CAMPOS. Da transcriação poética e semiótica da operação tradutora, p. 57.

${ }^{31}$ SCHURMANS. Entre história e ficção: o fracasso do homem de exceção. Une saison au Congo (Aimé Césaire) e Lumumba (Raoul Peck), p. 86.

${ }^{32}$ HALL. Cultural Identity and Cinematic Representation, p. 222.
} 
as tensões presentes nos bastidores". ${ }^{33}$ Longe de ser um profeta, Baldwin desmonta a lógica do racismo e, ainda que não responda aos dilemas apontados por ele mesmo e pelo diretor, responde a nossa pergunta inicial com sua lucidez sobre o mundo contemporâneo. Seus espectros rondam nossas cabeças na contemporaneidade não por uma tentativa de restauração de um passado eterno, daquilo que poderia ter sido, mas exatamente por uma tentativa de abrir um novo futuro diante das lutas contra o racismo e a desigualdade que ele gera.

\section{Referências}

BALDWIN, James. Nobody Knows My Name: More Notes of a Native Son. New York: Dial Press, 1961.

BALDWIN, James. Notes of a Native Son. New York: Bantam Books, 1968.

BALDWIN, James. The Devil Finds Work: An Essay. New York: Vintage Books, 1976.

BALDWIN, James. The Fire Next Time. New York: The Dial Press, 1963.

CAMPOS, Haroldo de. Da transcriação poética e semiótica da operação tradutora. In: OLIVEIRA, Ana Cláudia de; SANTAELLA, Lucia (Org.). Semiótica da Literatura. São Paulo: EDUC, 1987. p. 53-74.

COATES, Ta-Nehisi. Between the World and Me. New York: Random House, 2015.

DERRIDA, Jacques. Espectros de Marx: o estado da dívida, o trabalho do luto e a nova Internacional. Trad. Anamaria Skinner. Rio de Janeiro: Relume-Dumará, 1994.

DIDI-HUBERMAN, Georges. Quando as imagens tocam o real. Tradução [do espanhol] de Patrícia Carmello e Vera Casa Nova. Pós: Revista do Programa de Pós-graduação em Artes da Escola de Belas Artes da UFMG, Belo Horizonte, v. 2, n. 4, p. 204-219, nov. 2012.

DU BOIS, William Edward Burghardt. The Souls of Black Folk. New York: Dover, 1994.

\footnotetext{
${ }^{33}$ SCHURMANS. Entre história e ficção: o fracasso do homem de exceção. Une saison au Congo (Aimé Césaire) e Lumumba (Raoul Peck), p. 98.
} 
FANON, Frantz. Pele negra, máscaras brancas. Trad. Renato da Silveira. Salvador: EDUFBA, 2008.

FERREIRA, Luís Carlos. Livro \#Paremdenosmatar evidencia genocídio da população negra. Revista Fórum, Porto Alegre, 6 jan. 2017. Disponível em: <https://www.revistaforum.com.br/livro-parem-de-nos-matarevidencia-genocidio-da-populacao-negra/>. Acesso em: 27 mar. 2018.

FRANCISCO, Flávio Thales Ribeiro. A utopia pós-racial nos Estados Unidos: reestruturação do racismo e a ascensão de Barack Obama na era do colorblindness. Revista de História da UEG, Porangatu, v. 6, n. 1, p. 01-23, jan./jul. 2017.

HALL, Stuart. Cultural Identity and Cinematic Representation. Framework, Detroit, v. 36, p. 68-81, 1989.

HALL, Stuart. The Afterlife of Frantz Fanon: Why Fanon? Why Now? Why 'Black Skin, White Masks?' In: READ, Alan. The Fact of Blackness: Frantz Fanon and Visual Representation. London: Institute of Contemporary Arts and International Visual Arts, 1996, p. 6-20.

HALL, Stuart. The Spectacle of the 'Other'. In:__. Representation: Cultural Representation and Signifying Practices. London: Sage Publications, The Open University, 2002. p. 62-84.

I AM Not Your Negro. Direção: Raoul Peck. Produção: Remi Grellety, Raoul Peck, Hebert Peck. Paris: Velvet Film, 2016, 1 DVD (93min.).

MALRAUX, André. O museu imaginário. Lisboa: Edições 70, 2017.

MBEMBE, Achille. Necropolitics. Public Culture, Durham, NC, v. 15, n. 1, p. 11-40, 2003. doi: https://doi.org/10.1215/08992363-15-1-11

MBEMBE, Achille. O devir-negro do mundo. In: . Crítica da razão negra. Lisboa: Antígona, 2014. p. 10-39.

MORRISON, Toni. James Baldwin: His Voice Remembered; Life in His Language. The New York Times, New York, 1987. Books. Disponível em: <http://movies2.nytimes.com/books/98/03/29/specials/baldwinmorrison.html>. Acesso em: 27 mar. 2018.

PECK, Raoul (Ed.). I Am Not Your Negro: A Major Motion Picture Directed by Raoul Peck, from Texts by James Baldwin. New York: Vintage Books, 2017. 
PECK, Raoul. I Am Not Your Negro: Director Raoul Peck Talks Race, America, and Film. Newshub, 20 set. 2017. Entrevista concedida a Finn Hogan. Disponível em: <https://www.newshub.co.nz/home/ entertainment/2017/09/i-am-not-your-negro-director-raoul-peck-talksrace-america-and-film.html>. Acesso em: 27 mar. 2018.

PECK, Raoul. Introduction on a Personal Note. In: (Ed.). I Am Not Your Negro: A Major Motion Picture Directed by Raoul Peck, from Texts by James Baldwin. New York: Vintage Books, 2017. p. iii-xv.

PECK, Raoul. Notes on the Writing Process. In: (Ed.). I Am Not Your Negro: A Major Motion Picture Directed by $\overline{\text { Raoul Peck, from Texts }}$ by James Baldwin. New York: Vintage Books, 2017. p. xvii-xix.

SALGUEIRO, Maria Aparecida Andrade. A omissão como presença. Cult, São Paulo, ano 20, n. 222, p. 52-55, abr. 2017. Entrevista concedida a Helder Ferreira.

SCHURMANS, Fabrice. Entre história e ficção: o fracasso do homem de exceção. Une saison au Congo (Aimé Césaire) e Lumumba (Raoul Peck). Revista Crítica de Ciências Sociais, Coimbra, v. 106, p. 85-104, maio 2015.

SCOTT, A. O. Review: 'I Am Not Your Negro’ Will Make You Rethink Race. The New York Times, New York, 2 Feb. 2017. Disponível em: $<$ https://www.nytimes.com/2017/02/02/movies/review-i-am-not-yournegro-review-james-baldwin.html> . Acesso em: 27 mar. 2018.

STRAUSS, Alexandra. Editing I Am Not Your Negro. In: PECK, Raoul (Ed.). I Am Not Your Negro: A Major Motion Picture Directed by Raoul Peck, from Texts by James Baldwin. New York: Vintage Books, 2017, p. Xxii-Xxviii.

TILLIS, Antonio D.; HARRIS II, Emmanuel (Ed.). The Travon Martin in US: An American Tragedy. New York: Peter Lang Publishing, 2015.

WARBURG, Aby. Atlas Mnemosyne. Madrid: Akal, 2010.

WEST, Cornel. Race Matters. Boston: Beacon Press, 2001.

Recebido em: 29 de junho de 2018 Aprovado em: 20 de novembro de 2018 